TP Periodica Polytechnica Chemical Engineering

61(2), pp. 102-108, 2017

https://doi.org/10.3311/PPch.8535

Creative Commons Attribution (i)

RESEARCH ARTICLE

\section{A Kinetic Study on Photocatalytic and Sonophotocatalytic Degradation of Textile Dyes}

\author{
Tuba Yetim ${ }^{1 *}$, Taner Tekin ${ }^{2}$
}

Received 30 August 2015; accepted after revision 14 December 2015

\begin{abstract}
In the present study, an artificial effluent solution was used for investigating the degradation of dyestuffs by sonolytic, photocatalytic and sonophotocatalytic methods in the presence of $\mathrm{TiO}_{2}$. This solution contained the mixture of C. I. Acid Red 27, C. I. Disperse Red 92 and C. I. Acid Orange 10 dyestuffs. The effect of parameters such as initial concentration of dyestuffs, light intensity, the amplitude of sonolysis and temperature on the degradation processes was studied. When the degradation data of the three methods for constant parameters were compared after 80 min.; the degradation values were approximately 19, 68 and $82 \%$ for sonolytic, photocatalytic and sonophotocatalytic processes respectively. According the results purely sonolysis has an inconsiderable effect for the degradation of dyes. Also, when the parameters were applied for determining the kinetics of processes the sonophotocatalytic degradation rate followed pseudo-first order kinetics with respect to concentration of dyestuff analogously photocatalytic process. It was observed that the reaction rate accelerated in the presence of ultrasound energy in the course of the experiments. The most effective process was sonophotocatalytic on the degradation and an equation was derived including the effect of sonolysis for sonophotocatalytic degradation kinetics.
\end{abstract}

\section{Keywords}

photocatalysis, sonolysis, sonophotocatalysis, degradation kinetic

\footnotetext{
${ }^{1}$ Department of Chemical Engineering, Faculty of Engineering and Architecture, Erzurum Technical University, Erzurum, Turkey

${ }^{2}$ Faculty of Engineering, Department of Chemical Engineering, Atatürk University, 25240 Erzurum, Turkey

*Corresponding author, e-mail: tuba.yetim@erzurum.edu.tr
}

\section{Introduction}

Textile dye in high concentration is one of the most difficult constituents of the textile wastewater to treat. The type of dye in the effluent can vary daily, or even hourly, depending upon the variety of recipes, techniques, machinery, raw materials, and fabrics. Discharged dye effluents from the textile industries cause important environmental dangerous. The interest in making the dye effluents colorless has increased in the recently. The traditional physical methods (as adsorption and ultrafiltration) are commonly used for removing the pollutants. But these methods are not very destructive and they forward the organic compounds to another phase [1-6]. This phenomenon causes a secondary pollutant. Therefore the usage of photocatalytic processes has increased in the recent days and different studies have been carried out about this process.

In some studies sonolytic degradation process has been investigated beside photocatalytic process. Selli et al. [7] studied the efficiency of 1,4-dichlorobenzene degradation in water under photolysis, photocatalysis on $\mathrm{TiO}_{2}$ and sonolysis. They reported that the fastest degradation rate was attained under sonophotocatalytic conditions, with slightly higher energy. Also, they investigated the degradation of methyl tert-butyl ether in water with using the combined sonolysis and photocatalysis. They compared the effects of these processes and noticed that the optimal operating condition was afforded by the combined use of ultrasound and photocatalysis (sonophotocatalysis) under intermittent stirring, leading to MTBE degradation in the shortest time with the lowest energy consumption [8].

The photocatalytic process is an advanced oxidation process (AOP) involving the conversion of organic pollutants to short species and even to their complete mineralization through the generation of highly reactive free radical oxidants. Among destructive photocatalyst, titanium dioxide is one of the most effective and widely used. Titanium dioxide is inexpensive, stable, readily available and the most extensively studied semiconductor photocatalyst for the purification of water and air. For these reasons titanium dioxide has been used commonly for photocatalysis processes. Photoexcitation of $\mathrm{TiO}_{2}$ requires light with wavelengths of $\leq 380 \mathrm{~nm}$. Upon absorption of a photon by 
$\mathrm{TiO}_{2}$, an electron is promoted to the conduction band, generating what is commonly referred to as an electron-hole pair [9].

The conduction band electron is available for reduction and the valence band hole available for oxidation. The hole can subsequently react by electron transfer with a substrate to form a radical species or hydroxide (water) to form hydroxyl radical. In condensed oxygenated aqueous media the surface of $\mathrm{TiO}_{2}$ is completely hydroxylated and upon photoexcitation generates hydroxyl radical in an adsorbed state [10-13].

The hydroxyl radical is a powerful oxidizing agent and attacks to organic compounds and intermediates (Int.). These intermediates react with hydroxyl radicals $\left(\mathrm{OH}^{*}\right)$ to produce final products $(\mathrm{P})$, also hydroxyl radicals could be consumed by inactive species. In some studies the photocatalytic degradation of dyes has been reported as a mechanism; [14-17]

$$
\begin{gathered}
\mathrm{TiO}_{2}+\mathrm{h} v \stackrel{k 1}{\longrightarrow} \mathrm{e}^{-}+\mathrm{h}^{+} \\
\mathrm{e}^{-}+\mathrm{h}^{+} \stackrel{k 2}{\longrightarrow} \text { heat } \\
\mathrm{h}^{+}+\left(\mathrm{H}_{2} \mathrm{O}\right)_{\text {ads }} \stackrel{k 3}{\longrightarrow}\left(\mathrm{OH}^{*}\right)_{\text {ads }}+\mathrm{H}^{+} \\
\mathrm{h}^{+}+\mathrm{OH}_{\text {ads }}^{-} \stackrel{k 4}{\longrightarrow}\left(\mathrm{OH}^{*}\right)_{\text {ads }} \\
\left.\left(\mathrm{OH}^{*}\right)_{\text {ads }}+(\mathrm{Dye})_{\text {ads }} \stackrel{k 5}{\longrightarrow} \text { Int.(Intermediates }\right) \\
\left(\mathrm{OH}^{*}\right)_{\text {ads }}+\text { Int. } \stackrel{k 6}{\longrightarrow} \mathrm{P}(\text { final product }) \\
\left(\mathrm{OH}^{*}\right)_{\text {ads }}+\mathrm{S}_{\text {inactive }} \stackrel{k 7}{\longrightarrow} \text { Inactive species }
\end{gathered}
$$

In the photodegradation of dyes by UV radiation in the presence of $\mathrm{TiO}_{2}$, the rate-determining step is the reaction (5) between adsorbed $\mathrm{OH}^{*}$ radicals and dye according to this mechanism $[16,18]$. The kinetics of photocatalytic degradation follows the Langmuir-Hinshelwood model and the reaction rate follows pseudo-first order kinetics by considering the steady-state conditions and based on several other literature reports [15, 18-21]. The kinetic expression is showed in the following form [16]:

$$
\mathrm{r}_{\mathrm{D}}=\mathrm{k}_{5}\left[\mathrm{OH}^{\bullet}\right]_{\mathrm{ads}}\left[\mathrm{C}_{\mathrm{D}}\right]_{a d s}
$$

When the reaction rate equations written for all steps and some assumptions are predicted as;

$$
k_{8}=k_{3}\left[\mathrm{H}_{2} \mathrm{O}\right]_{\mathrm{ads}}-k_{4}\left[\mathrm{OH}^{-}\right]_{\mathrm{ads}}
$$

at low light intensities, $\mathrm{h}^{+}$trapping competes effectively with electron-hole recombination $[16,20]$. So;

$$
\begin{gathered}
k_{8}\left[h^{+}\right]>>k_{2}\left[h^{+}\right]\left[e^{-}\right] \\
{\left[h^{+}\right]=\frac{k_{1} I_{a}}{k_{8}}}
\end{gathered}
$$

When it is supposed that the deactivation of $\mathrm{OH}^{*}$ radicals with inactive surfaces $(\mathrm{S})$ is very important than other processes;

$$
\left[O H^{\bullet}\right]_{a d s}=\frac{k_{8}}{k_{7} S_{\text {inaktif }}}\left[h^{+}\right]=k^{\prime}\left[h^{+}\right]
$$

When the Eq. (8), (11) and (12) get combined;

$$
r_{D}=\frac{k^{\prime} k_{1} k_{5}}{k_{8}} I_{a}\left[C_{D}\right]_{a d s}
$$

reaction rate is obtained.

$$
k_{a}=\frac{k^{\prime} k_{1} k_{5}\left[C_{D}\right]_{a d s}}{k_{8}}
$$

If the Langmuir adsorption model is applied to this system;

$$
r_{D}=\frac{k_{a} I_{a} K_{D}\left[C_{D}\right]}{1+K_{D}\left[C_{D}\right]}
$$

Where $K_{D}$ is the adsorption equilibrium constant for dye. If the competitive adsorption by solvent, intermediates and pollutants are considered [16];

$$
K_{D}\left[C_{D}\right]+\sum K_{i} C_{i}=K_{D}\left[C_{D}\right]_{0}
$$

where $\mathrm{K}_{\mathrm{i}}$ is the adsorption equilibrium constant and $\mathrm{C}_{\mathrm{i}}$ is the concentration for solvent, intermediates and pollutants. $\left[C_{D}\right]_{0}$ is the initial concentration of dye $(\mathrm{mg} / \mathrm{l})$.

$$
r_{D}=\frac{k_{a} I_{a} K_{D}\left[C_{D}\right]}{1+K_{D}\left[C_{D}\right]_{0}}
$$

The degradation rate of dye is stated;

$$
\begin{aligned}
r_{D}=\left(\frac{-d C_{D}}{d t}\right) & =k_{P}\left(C_{D}\right)=\frac{k_{a} I_{a} K_{D}\left[C_{D}\right]}{1+K_{D}\left[C_{D}\right]_{0}} \\
k_{P} & =\frac{k_{a} I_{a} K_{D}}{1+K_{D}\left[C_{D}\right]_{0}}
\end{aligned}
$$

If it is considered that the used light intensity is constant;

$$
k_{c}=k_{a} I_{a}
$$

$$
k_{P}=k_{c}\left(\frac{K_{D}}{1+K_{D}\left(C_{D}\right)_{0}}\right)
$$

has been given. If this equation is lineared;

$$
\frac{1}{k_{P}}=\frac{1}{k_{c} K_{D}}+\frac{1}{k_{c}} C_{D o}
$$

is obtained.

When Eq. (22) is integrated for kinetic model;

$$
\ln \left(\frac{C_{D 0}}{C_{D}}\right)=k_{P} \cdot t
$$


is obtained. Where all the $\mathrm{k}$ 's are rate constants $\left(\mathrm{k}_{1}=\mathrm{mg}\right.$. $\mathrm{m}^{2} /$ (1.W.min.); $\quad \mathrm{k}_{2}=\mathrm{k}_{3}=\mathrm{k}_{4}=\mathrm{l} /($ mg.min. $) ; \mathrm{k}_{5}=\mathrm{k}_{6}=1 /(\mathrm{mg} \cdot \min$.$) ;$ $\mathrm{k}_{7}=1 /\left(\mathrm{m}^{2} \mathrm{~min}.\right) ; \mathrm{k}_{8}=\mathrm{k}_{\mathrm{p}}=1 / \mathrm{min}$; $\mathrm{k}^{\prime}=$ dimensionless; $\mathrm{k}_{\mathrm{a}}=\mathrm{mg} \cdot \mathrm{m}^{2} /$ (1.W.min.); $\mathrm{k}_{\mathrm{c}}=\mathrm{mg} /\left(1 . \mathrm{min}\right.$.)) $\mathrm{C}_{\mathrm{D}}$; dye concentration (mg/l), $\mathrm{C}_{\mathrm{D} 0}$; initial dye concentration $(\mathrm{mg} / \mathrm{l}), \mathrm{K}_{\mathrm{D}}$; adsorption equilibrium constant $(1 / \mathrm{mg})$, $t$; time (min.), $\mathrm{I}_{\mathrm{a}}$; light intensity $\left(\mathrm{W} / \mathrm{m}^{2}\right)$. It is also explained that the photocatalytic and the sonophotocatalytic degradation of dyestuffs follow pseudo-first order kinetics in other several studies [11, 15, 22].

The exposure of water to ultrasound results in local hot spots (4000-5000 K) as a consequence of the formation, growth and collapse of cavity bubbles containing entrapped gases and vapors of the surrounding water [23]. At collapse, chemical reactivity is initiated through thermolytic decomposition of bubble contents into free radical species, and/or through free radical oxidation of dissolved solutes at the gas-liquid interface or the bulk liquid [24-25]. The chain of reactions occurring during sonication of pure water is as the following [23]:

$$
\begin{gathered}
\mathrm{H}_{2} \mathrm{O} \stackrel{\text { Ultrasound }}{\longrightarrow} \mathrm{H}^{*}+\mathrm{OH}^{*} \\
\mathrm{OH}^{*}+\mathrm{OH}^{*} \longrightarrow \mathrm{H}_{2} \mathrm{O}_{2} \\
\mathrm{H}_{2} \mathrm{O}_{2}+\mathrm{H}^{*} \longrightarrow \mathrm{H}_{2} \mathrm{O}+\mathrm{OH}^{*}
\end{gathered}
$$

Ultrasonic irradiation has shown promise for the purification of contaminated water (or textile effluents) and involves at least in significant part standard hydroxyl radical mediated chain oxidation processes $[25,26]$.

The effect of sonolysis is based on the $\mathrm{OH}^{*}$ radicals which are occurred from the homolysis of $\mathrm{H}_{2} \mathrm{O}$. Ultrasonic irradiation has shown promise for the purification of contaminated water and involves at least in significant part standard hydroxyl radical mediated chain oxidation processes. Hydrogen atoms react with oxygen atoms $\left(\mathrm{H}^{*}+\mathrm{O}_{2} \rightarrow \mathrm{HO}_{2}^{*}\right)$ or undergo termination $\left(\mathrm{HO}^{*}+\mathrm{H}^{*} \rightarrow \mathrm{H}_{2} \mathrm{O}\right)$ and are generally not considered to be important in the degradation of organic substrates during sonolysis. The sonochemical treatment of a variety of organic pollutants yields low molecular weight carboxylic acids as the final products. [14, 27-28]

Three regions, gas phase, gas-liquid interface and bulk liquid solution are present during cavitation. The most extreme conditions are generated in the gas phase, commonly referred to as the hot-spot. Significantly, high temperature and pressure conditions produced at the gas-liquid interface can accelerate hydrolysis, eliminations, low temperature pyrolysis and supercritical water oxidation processes that are not observed from other AOTs. Changes to the bulk solution are relatively insignificant.

Ultrasonic technology is well advanced and used for a number of industrial applications (for cleaning, pigment dispersion, etc.). Versatility of ultrasonic irradiation should make it adaptable for the removal of problematic contaminants in aqueous phase. Despite the tremendous interest in the ultrasonic irradiation induced degradation of pollutants, much of the fundamental understanding and characterization of these complex processes are still at the preliminary stages [24-26, 29].

In this study, the effect of ultrasound energy (sonolysis) on the photocatalytic degradation of dyestuffs by UV radiation in the presence of $\mathrm{TiO}_{2}$ was observed. For this aim artificial effluent solutions that contained dyestuffs mixture of $C$. I. Acid Red 27, C. I. Disperse Red 92 and C. I. Acid Orange 10 were prepared. The degradation of these dyestuffs was investigated by sonolytic, photocatalytic and sonophotocatalytic methods in the presence of $\mathrm{TiO}_{2}$. Finally, a new kinetic equation containing the effect of sonolysis was derived for sonophotocatalytic degradation kinetics.

\section{Experimental}

The processes were performed in a Pyrex glass reactor. For sonolytic experiments an ultrasonic generator (Cole Parmer, Ultrasonic homogenizer, $750 \mathrm{~W}, 20 \mathrm{kHz}$ ) with a cup horn probe was used. Pen-Ray UV lamps (Cole Parmer, $44 \mathrm{~W} / \mathrm{m}^{2}$ ) were used as the radiation source for photocatalytic experiments. The water was circulated continuously within the water jacket reactor by the constant temperature water circulator to keep the temperature stability. The required $\mathrm{O}_{2}$ for system was procured from a vacuum pump.

The commercial titanium dioxide supplied by Degussa (P25) was used as photocatalyst. According to the manufacturer's specifications, P25 has an elementary particle size of 30 $\mathrm{nm}$, a BET specific surface area of $50 \mathrm{~m}^{2} / \mathrm{g}$ and its crystalline mode was $80 \%$ anatase and $20 \%$ rutile. The artificial effluent solution was prepared with the dyestuffs mixture of $C$. $I$. Acid Red 27, C. I. Disperse Red 92 and C. I. Acid Orange 10 were supplied from a textile fabric of Rasih Celik Corporation. These dyestuffs were used without further purification. The maximum of the absorbance spectrum of these dyestuffs mixture was determined as $499 \mathrm{~nm}$ by the UV-Vis spectrophotometer. Molecular formulas of these dyes and the absorbance spectrums of the artificial effluent solution are shown in Fig. 1.

The experiments were carried out with $300 \mathrm{ml}$ dye solutions prepared in appropriate concentrations by using deionized water. 30, 40, 50, $60 \%(32.36-43.03-49.03$ and $55.03 \mathrm{~W})$ amplitude of ultrasound energy and $20,30,40,50{ }^{\circ} \mathrm{C}\left( \pm 0.4{ }^{\circ} \mathrm{C}\right)$ temperatures were used for the experiments. The light intensities of 44, 88 and $132 \mathrm{~W} / \mathrm{m}^{2}$ were chosen. The reactor was isolated from the outside light. Different concentrations of dye solutions (20, 30, 35 and $40 \mathrm{ppm})$ and $200 \mathrm{mg} \mathrm{TiO} 2$ were introduced in this reactor. Solutions were stirred in the dark for 30 min. after the addition of the catalyst to equilibrate the system. $5 \mathrm{ml}$. samples of suspension were withdrawn at regular intervals and were immediately centrifuged at $6000 \mathrm{rpm}$ for $10 \mathrm{~min}$. to completely remove catalyst particles. Dye concentrations were analyzed by measuring the absorbance of the 
solution samples with UV-Vis spectrophotometer (Thermo Electron Evolution 500 spectrophotometer) at $\lambda_{\max }=499 \mathrm{~nm}$ for determining the degradation. Sonolytic, photocatalytic and sonophotocatalytic experiments were studied for displaying the effect of ultrasound.

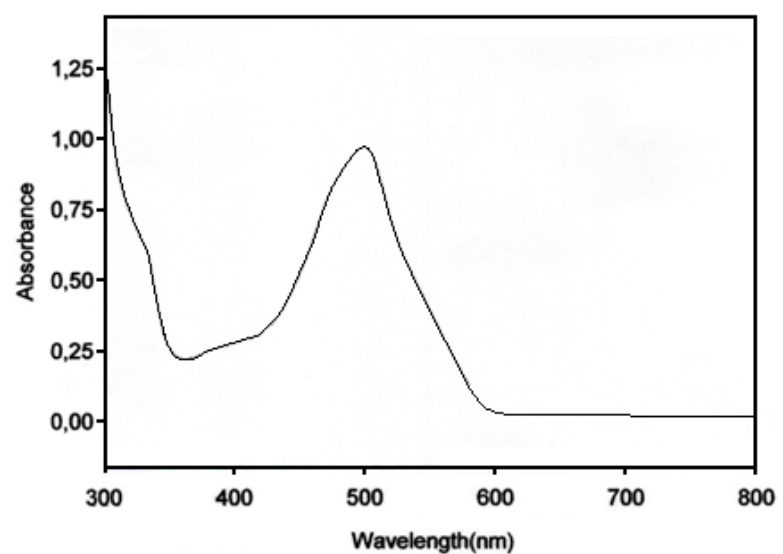

(a)

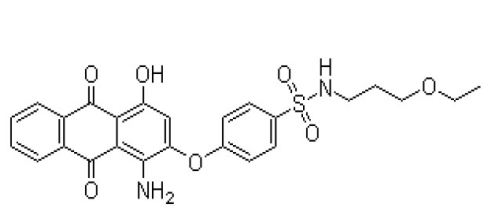

Disperse Red 92

$\mathrm{SO}_{3}$

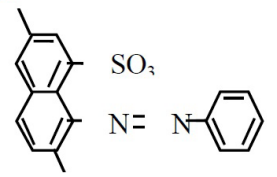

O

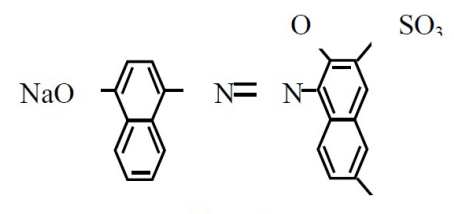

(b)

Fig. 1 (a) Absorbance spectrum of artificial effluent solution. (b) Molecular formula of the dyes in artificial effluent solution.

\section{Results and Discussion}

In this study, the initial dye concentration (30 ppm), temperature $\left(30{ }^{\circ} \mathrm{C}\right)$, amplitude of sonolysis $(30 \%)$ and light intensity $\left(44 \mathrm{~W} / \mathrm{m}^{2}\right)$ parameters were selected constant parameters for comparing the experimental data of sonolytic, photocatalytic and sonophotocatalytic processes.

The degradation data of the experiments for constant parameters were graphed in Fig. 2. After $80 \mathrm{~min}$. the degradation values were approximately 19, 68 and $82 \%$ for sonolytic, photocatalytic and sonophotocatalytic processes respectively. From the results it can be said that the purely sonolysis has an inconsiderable effect for the degradation of dyes.

All of the parameters selected for this study (initial dye concentration, temperature, amplitude of ultrasound energy and light intensity) were studied with ultrasound energy (sonophotocatalytic) and without ultrasound energy (photocatalytic).

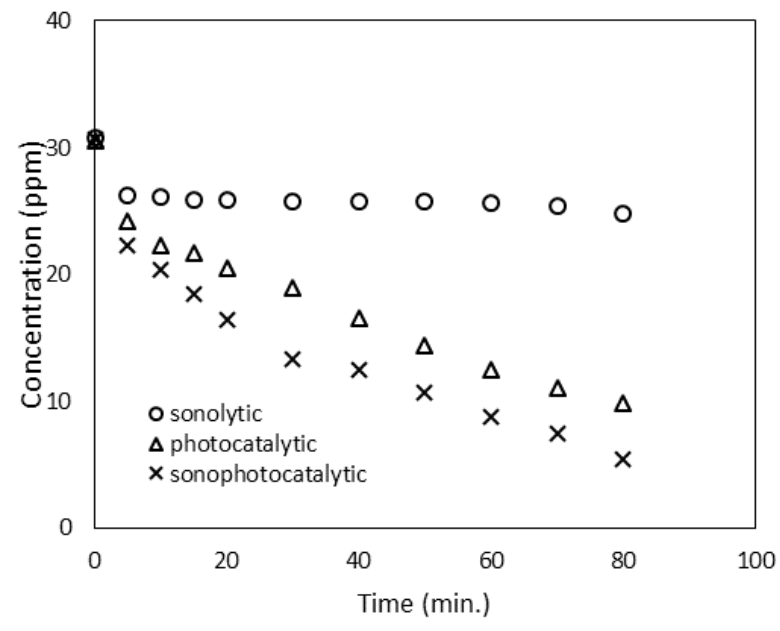

Fig. 2 The degradation of dyestuffs at the constant parameters (at $30^{\circ} \mathrm{C}$ temperature, $30 \%$ amplitude of sonolysis and $44 \mathrm{~W} / \mathrm{m}^{2}$ light intensity)

\subsection{Effect of Concentration}

The effect of initial dye concentration is an important parameter for degradation processes. The initial concentration values were $20,30,35$ and $40 \mathrm{ppm}$. The constant parameters were temperature $\left(30{ }^{\circ} \mathrm{C}\right)$, amplitude of sonolysis $(30 \%)$ and light intensity $\left(44 \mathrm{~W} / \mathrm{m}^{2}\right)$. Equation (23) shows a pseudo-first order reaction with respect to the concentration. The plot of the $\ln \left(\mathrm{C}_{\mathrm{D} 0} / \mathrm{C}_{\mathrm{D}}\right)$ versus time in the processes yield straight lines indicating pseudo-first order reaction (Fig. 3). $\mathrm{k}_{\mathrm{p}}$ values were calculated from experimental data using a regression analysis.

It was seen that the degradation rates decreased with increasing the initial concentration for all processes and the highest degradation rate was obtained from the sonophotocatalytic process as seen in Fig. 4. It is the reason of placing the more dye molecule on the catalyst surface by increasing the dye concentration. This state causes reducing the active sites for adsorbing the hydroxyl radicals. Thus the degradation ratio of dye reduces because of the less hydroxyl radicals.

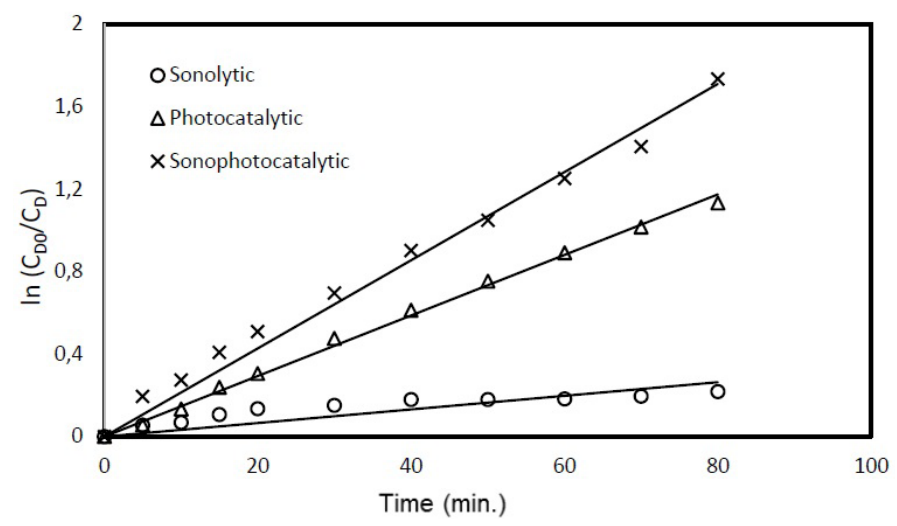

Fig. 3 Linear variation of $\ln \left(C_{D 0} / C_{D}\right)$ versus time for sonolytic, photocatalytic and sonophotocatalytic processes 
The Langmuir adsorption model used for rate constant $\mathrm{k}_{\mathrm{p}}$ is seen from the Eq. (22) [16]. $\mathrm{k}_{\mathrm{p}}$ is inversely proportional with the initial dye concentration when the other parameters are constant.

According to Eq. (22), the plot of $1 / \mathrm{k}_{\mathrm{p}}$ versus $\mathrm{C}_{\mathrm{D} 0}$ demonstrated in Fig. 4. It shows a linear variation, affirmed the Langmuir-Hinshelwood model. The values of $k_{c}$ and $K_{D}$ were calculated from the intercept and the slope of straight lines for photocatalytic and sonophotocatalytic processes. The adsorption equilibrium constant $\left(\mathrm{K}_{\mathrm{D}}\right)$ values were $0.155(\approx 0.16)$ and $0.157(\approx 0.16) \mathrm{L} / \mathrm{mg}$ for sonophotocatalytic and photocatalytic processes respectively. Also, $\mathrm{k}_{\mathrm{c}}$ values were determined as 0.44 and $0.37 \mathrm{mg} /$ (L.min.) for sonophotocatalytic and photocatalytic processes, respectively. The adsorption equilibrium constants remained the same for two processes. This can provide that the effect of sonolysis on the degradation is similar to photocatalysis effect as producing the $\mathrm{OH}^{*}$ radicals by cavitations not changing the structure of dye directly. Also, straight lines in Fig. 4 confirm the suitability of photocatalytic and sonophotocatalytic processes to Langmuir-Hinshelwood model.

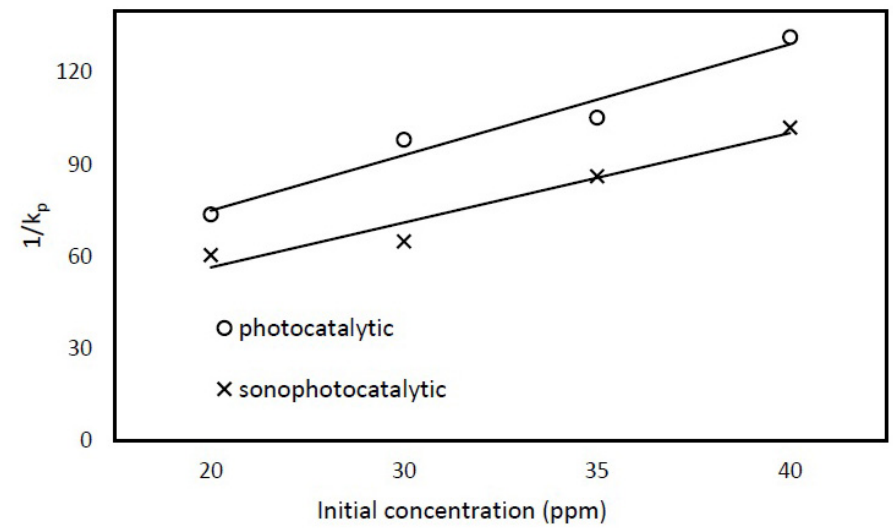

Fig. $41 / \mathrm{k}_{\mathrm{p}}$ versus concentration plot for photocatalytic and sonophotocatalytic processes

\subsection{Effect of Light Intensity}

The effect of light intensity was examined at constant initial concentration $(30 \mathrm{ppm})$, temperature $\left(30^{\circ} \mathrm{C}\right)$, amplitude of sonolysis $(30 \%) . \mathrm{k}_{\mathrm{p}}$ and light intensity $\left(\mathrm{I}_{\mathrm{a}}\right)$ were linear as seen from Eq. (19). The various light intensities $\left(44,88,132 \mathrm{~W} / \mathrm{m}^{2}\right)$ versus $\mathrm{k}_{\mathrm{p}}$ values is plotted (Fig. 5) for the photocatalytic and sonophotocatlytic processes. The linear curves prove the kinetic model. The photodegradation increased with the increasing light intensity. UV irradiation generates the required photons for the electron transfer from the valence to the conduction band of a photocatalyst. If more radiations are used, more hydroxyl radicals will be produced on the catalyst surface. In this case, degradation will increase [9]. When two processes are used together the degradation rate increases because of the cavitation are formed with sonolysis. When the cavitation collapses on the catalyst surface, they transfer their energy to the surface and more hydroxyl radicals are generated. As a result, the degradation rate increases by using sonolysis with increasing light intensity [30-31].

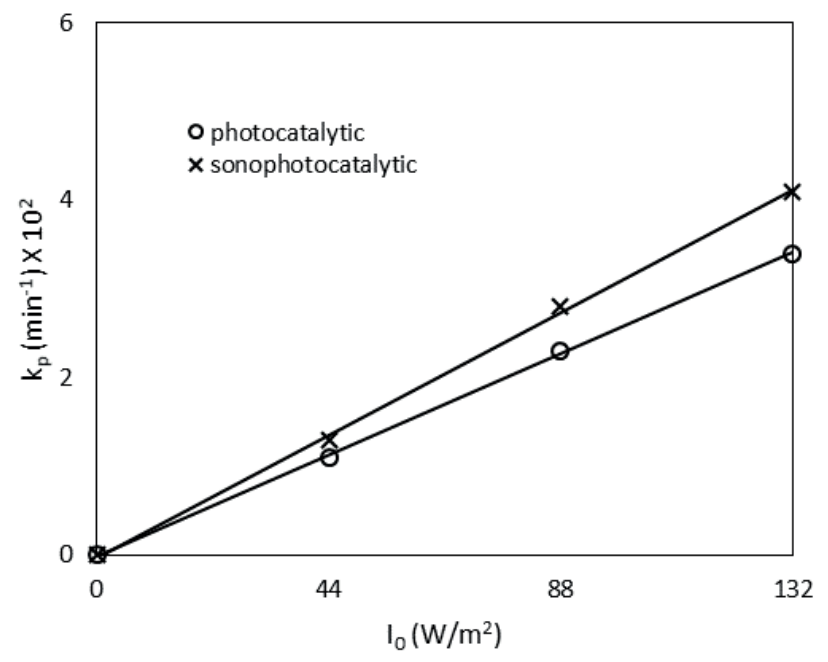

Fig. $5 \mathrm{k}_{\mathrm{p}}$ values versus light intensities for photocatalytic and sonophotocatalytic processes

\subsection{Effect of Temperature}

The temperature was studied at a constant concentration of $30 \mathrm{ppm}$, sonolysis amplitude of $30 \%$ and light intensity of $44 \mathrm{~W} / \mathrm{m}^{2}$. The temperature values were $20,30,40$ and $50{ }^{\circ} \mathrm{C}$ $\pm 0.4^{\circ} \mathrm{C}$. The degradation rate increased with the increase of temperature. It can be explained as the quantity of cavitation bubbles increase by the increase of the temperature [32]. When these bubbles collapse strongly on the catalytic surface, they can occur more holes and pores. The surface area of catalyst can increase through these holes and pores. Thus more $\mathrm{OH}^{*}$ radicals can occur on the catalyst surface.

The activation energy of the reaction is estimated from the Arrhenius plot (Fig. 6) as $65.4 \mathrm{~kJ} / \mathrm{mol}$ from photocatalytic experiments and $65.6 \mathrm{~kJ} / \mathrm{mol}$ from sonophotocatalytic experiments. It was thought that sonolysis didn't have an effect on the activation energy.

\subsection{Effect of amplitude}

The effect of amplitude experiments were performed at a constant concentration of $30 \mathrm{ppm}$, temperature of $30{ }^{\circ} \mathrm{C}$ and light intensity of $44 \mathrm{~W} / \mathrm{m}^{2}$. The sonolysis powers are detected as $32.36 ; 43.03 ; 49.03$ and $55.03 \mathrm{~W}$ for $20,30,40$ and $50 \%$ amplitude values respectively, by testing calorimetric method [33]. It can be seen from Fig. 7 that the degradation rate increased with the increment of amplitude. This can be explained with increasing the power of sonolysis and rising the amount of $\mathrm{OH}^{*}$ radicals. These radicals effect the degradation positively. Also, catalyst surfaces can be more cleaned at the higher powers of sonolysis. Thus, the surface area of catalyst can increase for forming more $\mathrm{OH}^{*}$ radicals. 


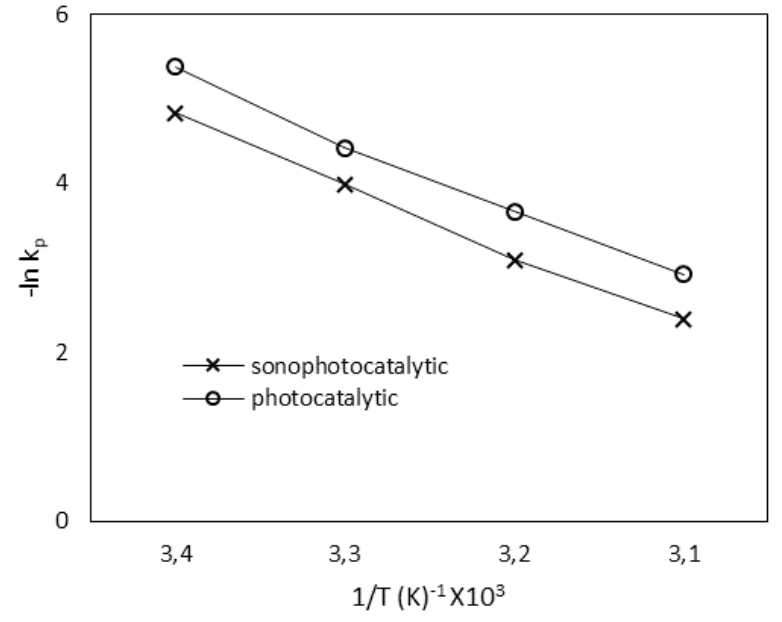

Fig. $6 \ln \mathrm{k}_{\mathrm{p}}$ versus 1/T graph

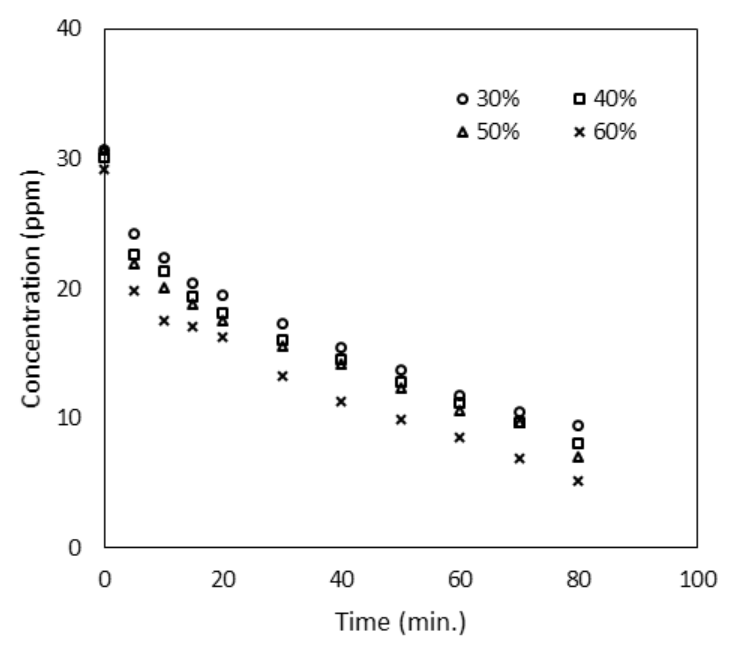

Fig. 7 Concentration change with amplitude of sonolysis

The dependence of reaction rate constant $\left(\mathrm{k}_{\mathrm{p}}\right)$ on sonolysis power is usually expressed with the following relation [20,34];

$$
k=A_{o}\left(1+b W_{U}\right)^{C} \exp (-E / R T)
$$

Sonolysis does not affect the activation energy. If the Eq. (27) and Eq. (19) are combined, the reaction rate constant $\left(\mathrm{k}_{\mathrm{p}}\right)$ will be as follows;

$$
k_{p}=A_{o}\left(1+b W_{U}\right)^{C} \cdot \exp (-E / R T) \cdot I_{a}\left(\frac{K_{D}}{1+K_{D}\left(C_{D}\right)_{0}}\right)
$$

where $\mathrm{A}_{0}, \mathrm{~b}, \mathrm{c}$ are constants, $\mathrm{W}_{\mathrm{U}}$; ultrasound power, $\mathrm{E}$; activation energy, R; gas constant, $\mathrm{T}$; temperature, $\mathrm{I}_{\mathrm{a}}$; light intensity, $\mathrm{K}_{\mathrm{D}}$; adsorption equilibrium constant, $\mathrm{C}_{\mathrm{D} 0}$; initial dye concentration.

$\mathrm{k}_{\mathrm{p}}$ values of different sonolysis powers, concentrations, light intensities and temperatures are used for calculating $\mathrm{A}_{\mathrm{o}}=2.1310^{9}$, $\mathrm{b}=0.015$ and $\mathrm{c}=0.045$ values by nonlinear regression analysis.

In this study the most effective process was sonophotocatalytic on the degradation. This can be attributed to the sonolysis as increment of catalytic performance by cleaning the catalyst surface. Thus, the chemical reactions can occur easily on the catalyst surface. Also, collapse of cavitation generated by sonolysis produced at high temperatures and pressures. They cause the forming of $\mathrm{OH}^{*}$ radicals by homolysis of water. Hence, much more $\mathrm{OH}^{*}$ radicals (generated from photocatalysis and sonolysis) are found in the medium, are required for degradation.

\section{Conclusions}

In this study, an artificial effluent solution containing the different dyestuffs mixture was used for investigating the degradation kinetics of dyestuffs by comparing the sonocatalytic, photocatalytic and sonophotocatalytic processes. The effects of some process parameters on the kinetics, the fastest process and an equation including the effect of sonolysis were investigated. The obtained results from this study can be summarized as follows:

- The sonocatalytic, photocatalytic and sonophotocatalytic processes followed Langmuir-Hinshelwood as pseudofirst order kinetics.

- The purely sonolysis has an inconsiderable effect for the degradation of dyes.

- It was obtained that the most effective process was sonophotocatalytic on the degradation due to generating the much more $\mathrm{OH}^{*}$ radicals in this process.

- Sonolysis didn't affect the activation energy of the degradation reaction. It was efficient on the reaction rate con$\operatorname{stant}\left(\mathrm{k}_{\mathrm{p}}\right)$.

- An equation including the effect of sonolysis was determined for sonophotocatalytic degradation kinetics as:

$$
\begin{aligned}
& \left(\frac{-d C_{\text {Dye }}}{d t}\right)= \\
& 3.19 \times 10^{7}\left(1+0.029 W_{U}\right)^{0.153} \cdot \exp (-7880 / T) \cdot I_{a}\left(\frac{0.156}{1+0.156\left(C_{D}\right)_{0}}\right)
\end{aligned}
$$

\section{Acknowledgements}

The project (105T258) presented in this article is supported by TUBITAK.

\section{References}

[1] Koczka, K., Mizsey, P. "New area for distillation: wastewater treatment." Periodica Polytechnica Chemical Engineering. 54(1), pp. 41-45. 2010. https://doi.org/10.3311/pp.ch.2010-1.06

[2] Kordouli, E., Bourikas, K., Lycourghiotis, A., Kordulis, C. "The mechanism of azo-dyes adsorption on the titanium dioxide surface and their photocatalytic degradation over samples with various anatase/rutile ratios." Catalysis Today. 252, pp. 128-135. 2015. https://doi.org/10.1016/j.cattod.2014.09.010

[3] Cai, L., Xu, T., Shen, J., Xiang, W. "Highly efficient photocatalytic treatment of mixed dyes wastewater via visible-light-driven AgI-Ag3PO4/ MWCNTs." Materials Science in Semiconductor Processing. 37, pp. 19-28. 2015. https://doi.org/10.1016/j.mssp.2014.12.064 
[4] Horváth, O., Szabó-Bárdos, E., Zsilák, Z., Bajnóczi, G. "Application of photocatalytic procedure combined with ozonation for treatment of industrial wastewater - a case study." Periodica Polytechnica Chemical Engineering. 56(2), pp. 49-54. 2012. https://doi.org/10.3311/pp.ch.2012-2.01

[5] Tang, W. Z., An, H. "UV/TiO, Photocatalytic Oxidation of Commercial Dyes in Aqueous Solutions." Chemosphere. 31(9), pp. 4157-4170. 1995. https://doi.org/10.1016/0045-6535(95)80015-D

[6] Kuo, W. S., Ho, P. H. "Solar photocatalytic decolorization of methylene blue in water." Chemosphere. 45(1), pp. 77-83. 2001. https://doi.org/10.1016/S0045-6535(01)00008-X

[7] Selli, E., Bianchi, C. L., Pirola, C., Cappelletti, G., Ragaini, V. "Efficiency of 1,4-dichlorobenzene degradation in water under photolysis, photocatalysis on $\mathrm{TiO}_{2}$ and sonolysis." Journal of Hazardous Materials. 153(3), pp.1136-1141. 2008. https://doi.org/10.1016/j.jhazmat.2007.09.071

[8] Selli, E., Bianchi, C. L., Pirola, C., Bertelli, M. "Degradation of methyl tert-butyl ether in water: effects of the combined use of sonolysis and photocatalysis." Ultrasonics Sonochemistry. 12(5), pp. 395-400. 2005. https://doi.org/10.1016/j.ultsonch.2004.04.003

[9] Ollis, D. F., Pelizzetti, E., Serpone, N. "Destruction of water contaminants." Environmental Science and Technology. 25(9), pp. 1522-1529. 1991. https://doi.org/10.1021/es00021a001

[10] Kun, R., Dékány, I. "The influence of the interfacial properties of composite catalyst material on the photocatalytic conversion of $\mathrm{TiO}_{2}$ layer silicates." Periodica Polytechnica Chemical Engineering. 53(2), pp. 31-40. 2009. https://doi.org/10.3311/pp.ch.2009-2.01

[11] Ertugay, N., Acar, F. N. "Sonocatalytic degradation of Direct Blue 71 azo dye at the presence Zero-Valent Iron (ZVI)." Desalination and water treatment. 51(40-42), pp. 7570-7576. 2013. https://doi.org/10.1080/19443994.2013.774296

[12] He, Y., Grieser, F., Ashokkumar, M. "The mechanism of sonophotocatalytic degradation of methyl orange and its products in aqueous solutions." Ultrasonics Sonochemistry. 18(5), pp. 974-980. 2011. https://doi.org/10.1016/j.ultsonch.2011.03.017

[13] González-García, J., Esclapez, M. D., Bonete, P., Hernández, Y. V., Garretón, L. G., Sáez, V. "Current topics on sonoelectrochemistry." Ultrasonics. 50(2), pp. 318-322. 2010. https://doi.org/10.1016/j.ultras.2009.09.022

[14] Yetim, T., Tekin, T. "Sonophotocatalytic Degradation Kinetics of an Azo Dye Amaranth." Journal- Chemical Society of Pakistan. 34(6), pp. 1397-1402. 2012.

[15] Volkova, A. V., Nemeth, S., Skorb, E. V., Andreeva, D. V. "Highly Efficient Photodegradation of Organic Pollutants Assisted by Sonoluminescence." Photochemistry and Photobiology. 91(1), pp. 59-67. 2015. https://doi.org/10.1111/php.12352

[16] Daneshvar, N., Rabbani, M., Modirshahla, N., Behnajady, M. A. "Kinetic modeling of photocatalytic degradation of Acid Red 27 in $\mathrm{UV}^{-} \mathrm{TiO}_{2}$ process." Journal of Photochemistry and Photobiology A: Chemistry. 168(12), pp. 39-45. 2004. https://doi.org/10.1016/j.jphotochem.2004.05.011

[17] Ahmeda, A. Y., Kandiel, T. A., Ivanova I., Bahnemann, D. "Photocatalytic and photoelectrochemical oxidation mechanisms of methanol on $\mathrm{TiO}_{2}$ in aqueous solution." Applied Surface Science. 319, pp. 44-49. 2014. https://doi.org/10.1016/j.apsusc.2014.07.134

[18] Mills, A., O’Rourke, C., Moore, K. "Powder semiconductor photocatalysis in aqueous solution: An overview of kinetics-based reaction mechanisms." Journal of Photochemistry and Photobiology A: Chemistry. 310, pp. 66-105. 2015. https://doi.org/10.1016/j.jphotochem.2015.04.011

[19] Mohammadi-Aghdam, S., Marandi, R., Olya, M. E., Mehrdad Sharif, A. A. "Kinetic modeling of BB41 photocatalytic treatment in a semibatch flow photoreactor using a nano composite film." Journal of Saudi Chemical Society. 18(4). pp. 317-326. 2014. https://doi.org/10.1016/j.jscs.2013.09.012
[20] Terzian, R., Serpone, N. "Heterogeneous photocatalyzed oxidation of creosote components: mineralization of xylenols by illuminated $\mathrm{TiO}_{2}$ in oxygenated aqueous media." Journal of Photochemistry and Photobiology A: Chemistry. 89(2), pp. 163-175. 1995.

https://doi.org/10.1016/1010-6030(94)04020-3

[21] Khezrianjoo, S., Revanasiddappa, H. D. "Langmuir-Hinshelwood Kinetic Expression for the Photocatalytic Degradation of Metanil Yellow Aqueous Solutions by $\mathrm{ZnO}$ Catalyst." Chemical Sciences Journal. 2012(CSJ-85), pp. 1-7. 2012. URL: http://astonjournals.com/manuscripts/Vol2012/CSJ-85_Vol2012.pdf

[22] Ollis, D., Silva, C. G., Faria, J. "Simultaneous photochemical and photocatalyzed liquid phase reactions: Dye decolorization kinetics." Catalysis Today. 240, pp. 80-85. 2015. https://doi.org/10.1016/j.cattod.2014.03.062

[23] Crum, L. A., Mason, T. J., Reisse, J. L., Suslick K. S. "Sonochemistry and Sonoluminescence." NATO ASI Series, Volume 524, Kluwer Academic, Dordreicht. 1999.

[24] Ince, N. H., Tezcanli, G., Belen R., Apikyan, I. G. "Ultrasound as a catalyzer of aqueous reaction systems: the state of the art and environmental applications." Applied Catalysis B: Environmental. 29(3), pp. 167-176. 2001. https://doi.org/10.1016/s0926-3373(00)00224-1

[25] Tezcanli-Güyer, G., Ince, N. H. "Individual and combined effects of ultrasound, ozone and UV irradiation: a case study with textile dyes." Ultrasonics. 42(1-9), pp. 603-609. 2004. https://doi.org/10.1016/j.ultras.2004.01.096

[26] Merouani, S., Hamdaoui, O., Boutamine, Z., Rezgui, Y., Guemini, M. "Experimental and Numerical Investigation of the Effect of Liquid Temperature on the Sonolytic Degradation of Some Organic Dyes in Water." Ultrasonics Sonochemistry. 28, pp. 382-392. 2015. https://doi.org/10.1016/j.ultsonch.2015.08.015

[27] Talebian, N., Nilforoushan, M. R., Mogaddas, F. J. "Comparative study on the sonophotocatalytic degradation of hazardous waste." Ceramics International. 39(5), pp. 4913-4921. 2013. https://doi.org/10.1016/j.ceramint.2012.11.085

[28] Monteagudo, J. M., Duran, A., San Martin, I., Garcia, S. "Ultrasoundassisted homogeneous photocatalytic degradation of Reactive Blue 4 in aqueous solution." Applied Catalysis B: Environmental. 152-153, pp. 59-67. 2014. https://doi.org/10.1016/j.apcatb.2014.01.014

[29] Park, J. H. "Photochemical degradation and toxicity reduction of methyl 1-[(butylamino)carbonyl]-1H-benzimidazol-2-ylcarbamate in agricultural wastewater: Comparative study of photocatalysis and sonophotocatalysis." Desalination. 249(2), pp. 480-485. 2009.

https://doi.org/10.1016/j.desal.2009.01.018

[30] Zhang, J., Nosaka, Y. "Photocatalytic oxidation mechanism of methanol and the other reactants in irradiated $\mathrm{TiO}_{2}$ aqueous suspension investigated by $\mathrm{OH}$ radical detection." Applied Catalysis B: Environmental. 166-167, pp. 32-36. 2015. https://doi.org/10.1016/j.apcatb.2014.11.006

[31] Shinde, S. S., Bhosale, C. H., Rajpure, K. Y., Lee, J. H. "Remediation of wastewater: Role of hydroxyl radicals." Journal of Photochemistry and Photobiology B: Biology. 141, pp. 210-216. 2014. https://doi.org/10.1016/j.jphotobiol.2014.10.015

[32] Tang, S. K., Teng, T. T., Alkarkhi, A. F. M., Li, Z. "Sonocatalytic Degradation of Rhodamine B in Aqueous Solution in the Presence of $\mathrm{TiO}_{2}$ Coated Activated Carbon." APCBEE Procedia. 1, pp. 110-115. 2012. https://doi.org/10.1016/j.apcbee.2012.03.019

[33] Horst, C., Chen, Y. S., Kunz, U., Hoffmann, U. "Design, modeling and performance of a novel sonochemical reactor for heterogeneous reactions." Chemical Engineering Science. 51(10), pp. 1837-1846. 1996. https://doi.org/10.1016/0009-2509(96)00227-8

[34] İngec, T., Tekin, T. "Effect of ultrasound on the production reaction kinetics of sodium thiosulfate." Chemical Engineering and Technology. 27(2), 150-153. 2004. https://doi.org/10.1002/ceat.200401905 